\title{
Regulation of the angiotensin II-p22phox-reactive oxygen species signaling pathway, apoptosis and 8-oxoguanine-DNA glycosylase 1 retrieval in hyperoxia-induced lung injury and fibrosis in rats
}

\author{
YU WANG ${ }^{1}$, YUXI ZHU ${ }^{2}$, YUDI ZHU ${ }^{3}$, ZHONGYI LU ${ }^{4}$ and FENG XU ${ }^{4}$ \\ ${ }^{1}$ Department of Pediatrics, Southwest Hospital of The Third Military Medical University, Chongqing 400038; \\ ${ }^{2}$ Department of Oncology, The First Affiliated Hospital of Chongqing Medical University, Chongqing 400016; \\ ${ }^{3}$ Department of Pharmacy; ${ }^{4}$ Pediatric Intensive Care Unit, Children's Hospital of \\ Chongqing Medical University, Chongqing 400014, P.R. China
}

Received August 15, 2015; Accepted January 13, 2017

DOI: $10.3892 /$ etm.2017.4429

\begin{abstract}
The present study was designed to explore the impact of hyperoxia on lung injury and fibrosis via the angiotensin II (AngII)-p22phox-reactive oxygen species (ROS) signaling pathway, apoptosis and 8-oxoguanine-DNA glycosylase 1 (OGG1) repair enzyme. Newborn Sprague-Dawley rats were randomly divided in the newborn air group, newborn hyperoxia group and newborn intervention group, the latter of which was administered the chymotrypsin inhibitor, 2-(5-formylamino-6-oxo-2-phenyl1, 6-dihydropyrimidine-1-yl)-N-[4-dioxo-1-phenyl-7-(2pyridyloxy)]2-heptyl-acetamide (NK3201). A group of adult rats also received hyperoxic treatment. Histomorphological changes in lung tissues were dynamically observed. AngII, ROS, angiotensin type 1 receptor $\left(A T_{l} R\right)$ and p22phox messenger RNA (mRNA) levels, and OGG1 and peroxisome proliferator-activated receptor- $\gamma(\operatorname{PPAR} \gamma)$ protein levels in the lung tissues were detected at various times after hyperoxia. Hyperoxia led to traumatic changes in the lungs of newborn rats that resulted in decreased viability, increased mortality, morphological changes and the apoptosis of alveolar type II epithelial cells (AT-II), as well as increased expression levels of AngII, $A T_{l} R$ and $p 22 p h o x$, which would ultimately lead to secondary diseases. NK3201 significantly inhibited the
\end{abstract}

Correspondence to: Dr Yuxi Zhu, Department of Oncology, The First Affiliated Hospital of Chongqing Medical University, 1 Youyi Road, Yuzhong, Chongqing 400016, P.R. China

E-mail: yuxizhucn@126.com

Professor Feng Xu, Pediatric Intensive Care Unit, Children's Hospital of Chongqing Medical University, 136 Zhongshan Er Road, Yuzhong, Chongqing 400014, P.R. China

E-mail: xuf2011@yeah.net

Key words: oxidative stress, angiotensin II, NK3201, human 8-oxoguanine-DNA glycosylase 1, peroxisome proliferator-activated receptor- $\gamma$ hyperoxia-induced increased expression of AngII, $A T_{l} R$ and p22phox and further promoted OGG1 and PPAR $\gamma$ protein expression, thus reducing the intrapulmonary ROS level, the apoptotic index and caspase-3 levels. However, the adult hyperoxia group only exhibited tachypnea and reduced viability. This study suggested that the AngII-p22phox-ROS signaling pathway, PPAR $\gamma$ and OGG1 together contributed to the hyperoxia-induced lung injury and that NK3201 was able to reverse the effects of hyperoxia.

\section{Introduction}

Respiratory diseases are the leading cause of disease in premature newborn babies $(1,2)$. Although the widely accepted use of high-oxygen technologies such as mechanical ventilation has improved neonatal survival rates, these technologies also cause apoptosis of alveolar type II (AT-II) cells, which play an important role in the repair of lung epithelial cells. Thus, hyperoxia-induced lung injury occurs, which is represented by pulmonary fibrosis. Therefore, neonates continue to require mechanical ventilation and oxygen therapy after their primary diseases have improved $(3,4)$.

In recent years, angiotensin II (AngII), an important factor that functions in multiple pathways in physiological and pathological processes, has been studied in depth. AngII receives signals from renin and induces the production of mitochondrial reactive oxygen species (ROS). ROS induce endothelial dysfunction, cardiovascular and renal remodeling, inflammation and fibrosis. Previous studies have shown that AngII is closely associated with fibrosis in multiple organs $(4,5)$. As pulmonary fibrosis results in a severe prognosis for newborns after hyperoxic treatment, AngII-induced ROS are thought to be a factor that should be considered in relation to the formation of pulmonary fibrosis $(6,7)$. ROS are derived from nicotinamide adenine dinucleotide phosphate (NADPH) oxidase through redox processes (8). Thus, the associations among the AngII-p22phox-ROS pathway, vascular remodeling and fibrosis have garnered attention (9). In addition, ROS induce pulmonary cell apoptosis, leading to hyperoxia-induced lung injury (7). Moreover, renin may 
regulate the AngII-p22phox-ROS pathway, thereby exerting its actions towards AT-II cells and participating in the regulation of hyperoxia-induced lung injury and fibrosis (10).

However, some mechanisms are utilized to protect the body from damage by stress. The peroxisome proliferator-activated receptor- $\gamma(\operatorname{PPAR} \gamma)(11)$, and active repair enzyme, human 8-oxoguanine-DNA glycosylase (hOGG1) (12), may be viewed as protective factors. PPAR $\gamma$ can decrease apoptosis and regulate inflammation and metabolism. Additionally, hOGG1 can directly repair damage to the DNA. Thus, the statuses and roles of PPAR $\gamma$ (11) and hOGG1 (12) in lung injury repair have also garnered attention.

In order to explore the complicated relationship between these important factors and pathways under hyperoxia, and the consequent cell damage, in vivo experiments were designed using newborn rats. The reactions of the rats following hyperoxic treatment and the changes in the levels of these factors were analyzed. Moreover, the chymotrypsin inhibitor, NK3201, was utilized to determine whether it was able to reverse the effects of hyperoxia. Therefore, this study was designed to explore the interactions between the renin-angiotensin system (RAS) and repair factors in hyperoxia-induced lung injury and fibrosis, with the aim of providing experimental evidence to improve the prognosis of hyperoxia-induced lung injury.

\section{Materials and methods}

Animals. A total of 90 full-term newborn Sprague Dawley (SD) rats (male:female, 1.00:1.20) and 30 adult rats (male:female, 1.00:1.14) were provided by the Experimental Animal Center of Chongqing Medical University (Chongqing, China). Rats were raised in single cages in an environment without strong light or noise with a 12-h light/dark cycle and free to feed and water. This study was carried out in strict accordance with the recommendations in the Guide for the Care and Use of Laboratory Animals of the National Institutes of Health (8th edition, 2010). The animal use protocol has been reviewed and approved by the Institutional Animal Care and Use Committee (IACUC) of Chongqing Medical University.

Model preparation and grouping. Ninety 3-day-old full-term neonatal SD rats, with an average weight of $13.26 \pm 0.13 \mathrm{~g}$, were randomly divided into the neonatal air group (group A), neonatal hyperoxia group (group B) and neonatal intervention group (group C), with 30 rats in each group. In total, 30 90-day-old adult SD rats, with an average weight of $344.62 \pm 1.07 \mathrm{~g}$, were used to form the adult hyperoxia group (group D).

Rats in groups B, C, and D were individually caged and placed inside a high oxygen culture chamber for the continuous inhalation of high-concentration oxygen. The oxygen volume percentage inside the culture chamber was maintained at $90 \pm 2 \%$, monitored using a digital oxygen analyzer (OM-25ME-type oxygen analyzer; Maxtec, Salt Lake City, UT, USA), and recorded every $6 \mathrm{~h}$. Soda lime was used to absorb the $\mathrm{CO}_{2}$ generated, with the $\mathrm{CO}_{2}$ concentration maintained at $<0.5 \%$. The temperature was maintained at $23-25^{\circ} \mathrm{C}$, and the humidity was within 50-60\%. Group A inhaled fresh air and the remaining experimental factors were the same as those for the model group, group B (13). On days 1, 3, 7, 14 and 21 of the experiment, 6 rats from each group were randomly selected. Following anesthetization by intraperitoneal injection of $10 \%$ chloral hydrate (3 ml/kg; Sigma-Aldrich; Merck Millipore, Darmstadt, Germany), the rats were executed by cervical dislocation.

Rats in group C were injected with NK3201 (5 mg/kg/day; using a $5 \mathrm{mg} / \mathrm{ml}$ suspension with saline), purchased from Sigma-Aldrich (Merck Millipore), through the tail vein for 7 consecutive days following the beginning of hyperoxic exposure.

Specimen collection. Six rats from each group were randomly selected and euthanized on days 1,3, 7, 14 and 21 of the experiment. The bilateral lung tissues were preserved for microscopy, electron microscopy, and tissue-associated molecular examinations $(13,14)$.

Identification of successful hyperoxia models. Impacts on the survival rate and general state of the rats were recorded. The reaction indicators, including skin color, degree of dyspnea, foraging ability, food intake, weight gain, abnormal reactions after deoxygenation and after the resumption of oxygen, and mortality were recorded daily during the experiment.

Morphological observations. General morphological observation by hematoxylin and eosin (H\&E) staining was performed under a light microscope. Six sections from rats from each group were randomly selected at each time point and five fields in each section were randomly selected for the pathological examination.

Ultrastructural observation by transmission electron microscopy (TEM). The observation was performed using the JEM-1400 TEM (JEOL, Ltd., Tokyo, Japan). Specifically, small fragmented tissues (volumes: $1 \mathrm{x} 1 \mathrm{x} 1 \mathrm{~mm}$ ) were fixed for $>2 \mathrm{~h}$ with $2.5 \%$ glutaraldehyde, then fixed for $1-2 \mathrm{~h}$ with $1 \%$ osmic acid fixation ( $\mathrm{pH}$ 7.3-7.4). After acetone gradient dehydration and Epon 812 embedding, the thin slices were cut with a microtome (LKB4800A; Micron Technology, Inc., Munich, Germany), and observed by JEM-1400 TEM.

Determination of AngII content. AngII content was measured using a radioimmunoassay analysis kit (8758401; Ortho-Clinical Diagnostics, Inc., Rochester, NY, USA) , following the manufacturer's instructions: i) To $\sim 50 \mathrm{mg}$ lung tissues preserved at $-80^{\circ} \mathrm{C}$ was added $2 \mathrm{ml} \mathrm{PELH}$ diluent (including $0.1 \mathrm{~mol} / \mathrm{l} \mathrm{PBS}$, $3 \mathrm{mmol} / 1 \mathrm{EDTA}, 0.002 \%$ chlorhexidine and $0.196 \mathrm{mmol} / 1$ lysozyme, pH 7.6); ii) $40 \mathrm{ml}$ mixed enzyme was added, and $20 \%$ tissue homogenate was obtained following ultrasonic grinding using an UP-200H tissue homogenizer (Hielscher Ultrasonics, $\mathrm{GmbH}$, Teltow, Germany). Supernatant was collected after low temperature centrifugation $\left(256 \times \mathrm{g} ; 4^{\circ} \mathrm{C} ; 20 \mathrm{~min}\right)$. iii) Supernatant and RIA buffer solution were mixed, $50 \mathrm{ml}$ tracer material ( ${ }^{125} \mathrm{I} \_$Ang II; 4,000 cpm) and AngII antiserum were added, and the mixture was incubated for $20 \mathrm{~h}$ at $4^{\circ} \mathrm{C}$; iv) The mixed liquor was measured using an SN-695B gamma counter (Shanghai Hesuo Rihuan Photoelectronic Instruments Co., Ltd., Shanghai, China). v) A standard curve was established, and an unknown concentration could be determined using the standard curve (pg/ml). 
Reverse transcription-polymerase chain reaction ( $R T-P C R)$. The TRIzol One-step method (TRIzol-100 extraction liquid; Jingmei Biotech Co., Ltd., Shenzhen, China) was used to extract total RNA from the lung tissues. According to the manufacturer's instructions, $2 \mu \mathrm{l}$ of RQ1 RNase-Free DNase (Promega, WI, USA) was used to treat the samples and the total RNA was then reversely transcribed into cDNA using Oligo (dT) primer and Superscript II reverse transcriptase (Thermo Fisher Scientific, Inc., Waltham, MA, USA). The primers used were as follows. p22phox forward, 5'-ACTCCCATTGAGCCT AAACC-3' and reverse, 5'-GGAGCAACACCTTGGAAAC-3'; expected product, $226 \mathrm{bp}$; angiotensin type 1 receptor $\left(A T_{I} R\right)$ forward, 5'-CACCCTGTCTTGGCACCT-3' and reverse, 5'-TCGCCTCGCTTCCTACTG-3'; expected product, 335 bp; internal reference glyceraldehyde-3-phosphate dehydrogenase (GAPDH; internal control) forward, 5'-ACCACAGTCCAT GCCATCAC-3' and reverse, 5'-TCCACCACCCTGTTGCTG TA-3'; expected product, $452 \mathrm{bp}$.

PCR amplification was conducted using SYBR Green qPCR MasterMix (Thermo Fisher Scientific, Inc.) and the thermal conditions were as follows: Initial denaturation at $95^{\circ} \mathrm{C}$ for $5 \mathrm{~min}$, denaturation at $94^{\circ} \mathrm{C}$ for $1 \mathrm{~min}$, extension at $72^{\circ} \mathrm{C}$ for $1 \mathrm{~min}$ for 30 cycles, and a final extension at $72^{\circ} \mathrm{C}$ for $10 \mathrm{~min}$. Amplified PCR products were confirmed using a $1.5 \%$ agarose gel by UV visualization following ethidium bromide staining.

The optical density ratio (OD) to the GAPDH amplified fragment was used to express the relative amount of the above two mRNAs $(13,14)$.

Detection of ROS levels. ROS levels were determined as previously described $(13,14)$. 2',7'-Dichlorofluorescin diacetate (DCFH-DA) presents green fluorescence following ROS oxidation in cells. Lung tissues were incubated for $0.5 \mathrm{~h}$ in DCFH-DA solution $\left(2 \times 10^{6} \mathrm{~mol} / \mathrm{l}\right)$ with avoidance of light in a $37^{\circ} \mathrm{C}$ incubator. Fluorescence intensity was determined using laser scanning confocal microscopy (emission wavelength, $535 \mathrm{~nm}$ ), and ROS in the lung tissues were detected in situ.

Detection of alveolar epithelial cell apoptosis-related indicators. Detection of alveolar apoptotic cells was performed using the terminal deoxynucleotidyl transferase (TdT)-mediated dUTP nick end labeling (TUNEL) assay. Positive cells were observed under a light microscope at x400 magnification and exhibited brownish yellow-stained nuclei. Ten fields in each section were randomly observed to calculate the percentage of positive cells and the average number was considered as the apoptosis index (AI) $(13,14)$.

Detection of alveolar caspase-3 protein expression by immunohistochemistry. The caspase-3 antibody (caspase-3 rabbit anti-rat antibody; sc-7148; Santa Cruz Biotechnology, Inc., Dallas, TX, USA) was used. Immunohistochemical analysis was performed using a two-step detection kit (PV-9001; Zhongshan Jinqiao Biotechnology Co., Beijing, China). i) Tissue slices were gradient hydrated using absolute ethyl alcohol, 95\% ethyl alcohol and 70\% ethyl alcohol for $5 \mathrm{~min}$, respectively, after dewaxing by soaking in xylene repeatedly for $20 \mathrm{~min}$ and placing at room temperature for $60 \mathrm{~min}$. The slices were washed twice with PBS for 5 min each time. ii) Freshly prepared $3 \% \mathrm{H}_{2} \mathrm{O}_{2}$ in distilled water or PBS was used to quench endogenous peroxidase activity through treatment for 5-10 $\mathrm{min}$, and the slices were then washed three times with distilled water, for 2 min each time. iii) Antigen retrieval was conducted by heating with $0.01 \mathrm{M}$ sodium citrate buffer solution ( $\mathrm{pH}$ 6.0) in a microwave oven. iv) The slices were treated with primary antibody (1:200) overnight in a $4^{\circ} \mathrm{C}$ refrigerator; v) Incubation with horseradish peroxidase (HRP)-labeled goat anti-rabbit $\operatorname{IgG}(1: 1,000$; ab6721; Abcam, Cambridge, MA, USA) for $1 \mathrm{~h}$ at room temperature, followed by vi) treatment with streptavidin biotin-peroxidase complex reagent for $20 \mathrm{~min}$ at $20-37^{\circ} \mathrm{C}$ and vii) coloration using diaminobenzidine chromogenic reagent. viii) The slices were washed using distilled water and counterstained using hematoxylin for $2 \mathrm{~min}$. ix) Finally, the slices were dehydrated. Positive cells, observed under a light microscope, presented a brownish yellow-stained cytoplasm and nucleus. The OD value was measured. For each specimen, five sections were selected. Five fields in each section were randomly selected and the average OD value was used to represent the protein expression level.

Western blot analysis. The cryopreserved right side lung tissues were harvested and used for western blot analysis as previously described (15). i) The right rat lung tissues conserved at $-70^{\circ} \mathrm{C}$ were homogenized by adding radioimmunoprecipitation assay lysis buffer containing phenylmethylsulfonyl fluoride. ii) Quantification was conducted using Coomassie brilliant blue following centrifugation at $256 \times \mathrm{g}$; iii) Equivalent total proteins $(50 \mathrm{mg}$ ) were obtained from each sample, and they were transferred to nitrocellulose membranes using $10 \%$ SDS-polyacrylamide gel electrophoresis (PAGE); iv) rabbit anti-rat hOGG1 (GTX20204; GeneTex, Inc., Irvine, CA, USA) and rabbit anti-rat PPAR $\gamma$ (ab209350; Abcam primary antibodies were diluted to 1:1,000 and incubated with the membrane overnight at $4^{\circ} \mathrm{C}$; v) HRP-labeled goat anti-rabbit IgG (ab6721; 1:1,000; Abcam) secondary antibody was incubated at room temperature with the membrane for $1 \mathrm{~h}$; vi) enhanced chemiluminescent substrate was added for coloration for $15 \mathrm{~min}$. The integrated ODs of the bands were analyzed using ImageMaster software (v1.0.3.7) with the Bio-Rad Gel Doc1000 imaging system (Bio-Rad Laboratories, Inc., Hercules, CA, USA). The imaging system was used to acquire images of the X-ray films and the analysis software was used to analyze and calculate the integrated ODs $(13,16)$.

Statistical analysis. Univariate correlation analysis was used for correlation analyses. Intragroup comparisons were assessed using single-factor analysis of variance. Intergroup comparisons were performed using t-tests and rate comparisons were determined using the $\chi^{2}$ test. All statistical analyses were performed using SPSS version 11.3 statistical software (SPSS, Inc., Chicago, IL, USA), with $\mathrm{P}<0.05$ considered to indicate a statistically significant difference.

\section{Results}

General description of the hyperoxia-lung injury rat model. Group B exhibited abnormalities generally 3-5 days after hyperoxia, including decreased vitality and listlessness. On 
days 10-14, some rats presented breathing difficulties and head tremors when the oxygen supply was withdrawn. In severe situations, convulsions were observed and the number of deaths significantly increased. Animals in group A (control group) were healthy and did not present these symptoms. Animals from group D only presented tachypnea and decreased vitality. The damage induced by hyperoxia was decreased by the administration of NK3201 to animals in group C compared with the damage observed in animals from group B (Table I).

Morphological changes. Hyperoxia-induced pathological changes of the lung tissues were observed under a light microscope. No abnormal changes were observed in the lung tissues of group A animals. One day after hyperoxic exposure, no marked difference was observed between group A and group $\mathrm{B}$, while 3 days after hyperoxic exposure, lung tissues from the rats in group B exhibited dilation and congestion of small blood vessels, minor bleeding in the alveolus or septum, neutrophil infiltration, alveolar interstitial edema and alveolar exudate. At 7 days after hyperoxic exposure, the pulmonary lesions of the rats in group B reached a peak, exhibiting the comprehensive appearance of acute lung injury (ALI). At 21 days, the acute exudate was notably reduced, and the rats exhibited the initiation of lung septal thickening and fibrosis. The severity of the symptoms was significantly reduced in the lung tissues from group C compared with those in group B (Fig. 1).

Ultrastructural changes were also analyzed. In comparison with normal tissue (Fig. 2A), TEM indicated that prolonged hyperoxic exposure worsened the lesions in the hyperoxia groups, and also revealed that the histic electron densities were gradually reduced. The number of AT-II cells decreased. AT-II cells presented a significant edema of the endoplasmic reticulum and mitochondria inside the cytoplasm. Pulmonary interstitial edema and consolidation gradually increased, together with leukocyte infiltration, alveolar damage, reduction of residual alveolar volume, thinning and excessive expansion of the alveolar epithelium (Fig. 2B). As the disease progressed, the edema and hyperemia inside the cells and interstitial tissues further increased and fibrosis began to appear (Fig. 2C). Comparison among the groups revealed that the lesions of AT-II cells in group B were the most evident. Fibrosis was significantly decreased in specimens from group D compared with that of the specimens from groups $\mathrm{B}$ and $\mathrm{C}$, indicating that the impact of hyperoxia on newborn rat lung tissues was clearly greater than that on the adult lung tissues. NK3201 intervention in group C markedly reduced the tissue lesions, although not to the adult levels. The molecular mechanisms of these phenomena were investigated and are reported below.

Pulmonary AngII changes over time. As shown in Fig. 3 and Table II, hyperoxia increased AngII levels, and the levels increased over time in group B, reaching a peak on day 14, after which they gradually dropped to a relatively stable level. In contrast with the morphology of the lung tissues and the general state of the animals, the AngII level in group B was lower than that in group D on day 21, as shown in Fig. 3A. However, the AngII expression level in group C was significantly decreased compared with that in group B, and the time 




Figure 1. Changes of lung tissues over time after hyperoxic exposure (hematoxylin and eosin staining; magnification, x100). (A) Normal lung tissue (group A). (B) Infiltration of a large number of neutrophils (day 3, group B); (C) pulmonary edema (day 7, group B); (D) comprehensive appearance of acute lung injury (day 7, group B); (E) pulmonary interstitial fibrosis (day 21, group B) in the hyperoxic group.
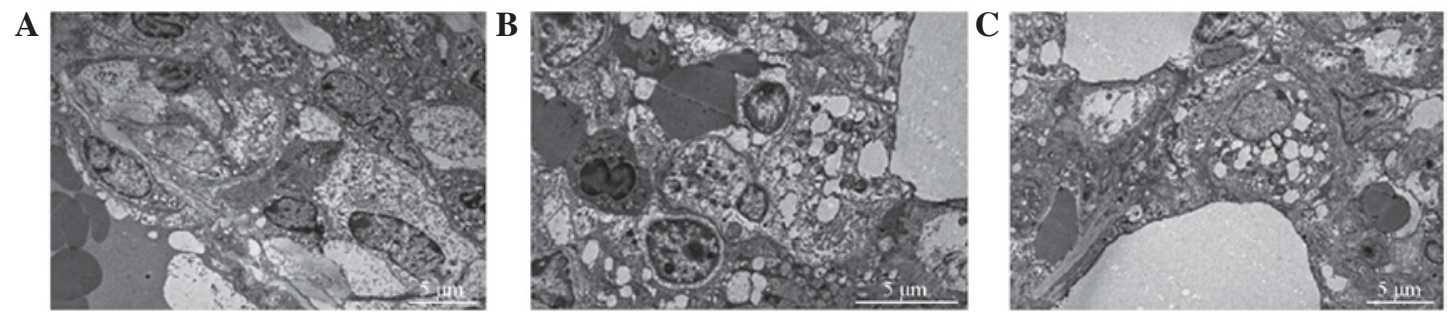

Figure 2. Electron microscopic changes of AT-II cells after hyperoxic exposure. (A) Normal lung tissue (day 1, group A; magnification, x4,000). (B) ultrastructural appearance of hyperoxia-induced lung injury (day 1, group B; magnification, x6,000); endoplasmic reticulum and mitochondria edema, interstitial congestion and residual alveolar volume were visible in the AT-II cytoplasm. (C) The lung injury was gradually increased with prolonged hyperoxic exposure time (day 7, group B; magnification, x4,000). The number of AT-II cells was decreased, the endoplasmic reticulum and mitochondria edema were visible within the cytoplasm, the electron density was decreased, a large number of mesenchymal cells exhibited edema, and a large quantity of fibrous tissue and leukocyte infiltration could be seen within the interstitium. The alveoli appeared damaged, the alveolar septum was thinned, and the epithelium was excessively expanded. AT-II, alveolar type II.
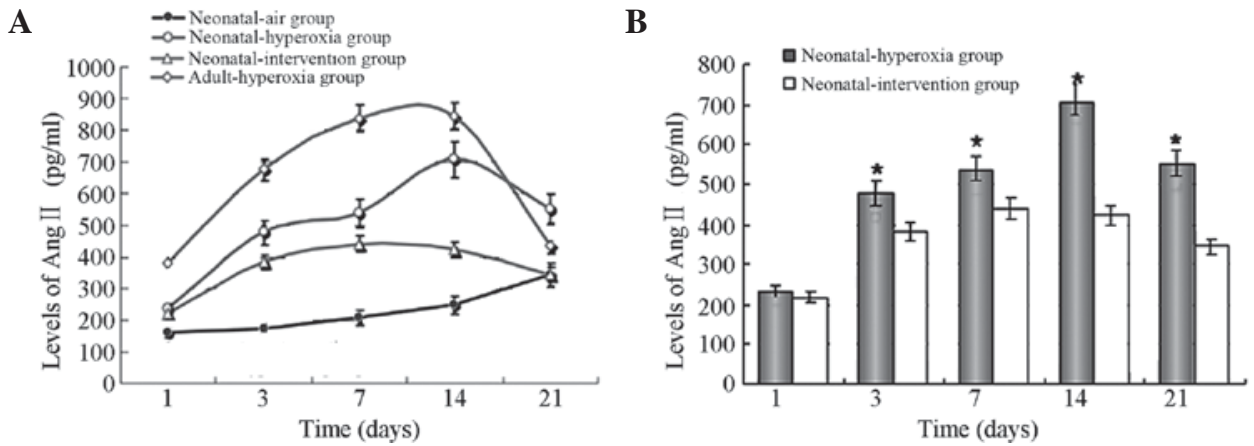

Figure 3. AngII changes under hyperoxia treatment and/or the chymotrypsin inhibitor NK3201. (A) Graph showing AngII level changes over time after hyperoxic exposure. (B) Inhibitory effects of NK3201 on AngII expression levels "P $<0.05$ vs. the neonatal-intervention group. AngII, angiotensin II.

point at which AngII levels began to decrease was observed earlier, on day 7 instead of day 14, indicating that NK3201 rapidly and significantly inhibited the hypoxia-induced AngII increase (Fig. 3B).

$A T_{1} R$ and p22phox mRNA levels. The $A T_{1} R$ and p22phox mRNA levels of the four groups are presented in Table III. The $A T_{l} R$ and p22phox mRNA levels in group B gradually increased with increasing time. However, in the late stage, the p22phox mRNA level exhibited a declining trend, similar to that observed for AngII. Although the increasing amplitude of $A T_{1} R$ slowed down in the late stage, it continued to increase until day 21. The $A T_{I} R$ and p22phox mRNA levels in group A did not show similar changes.

The $A T_{l} R$ and p22phox mRNA levels in group B were significantly increased in comparison with the levels in 
Table II. Levels of angiotensin II in rat lung tissues $(n=6)$.

\begin{tabular}{lcccc}
\hline $\begin{array}{l}\text { Time } \\
(\text { day })\end{array}$ & $\begin{array}{c}\text { Neonatal-air } \\
\text { group }(\mathrm{pg} / \mathrm{ml})\end{array}$ & $\begin{array}{c}\text { Neonatal-hyperoxia } \\
\text { group }(\mathrm{pg} / \mathrm{ml})\end{array}$ & $\begin{array}{c}\text { Neonatal-intervention } \\
\text { group }(\mathrm{pg} / \mathrm{ml})\end{array}$ & $\begin{array}{c}\text { Adult-hyperoxia } \\
\text { group }(\mathrm{pg} / \mathrm{ml})\end{array}$ \\
\hline 1 & $160.20 \pm 41.43$ & $233.55 \pm 54.55$ & $219.20 \pm 20.19$ & $378.39 \pm 53.91$ \\
3 & $170.25 \pm 25.16$ & $476.87 \pm 38.83^{\mathrm{a}}$ & $382.53 \pm 45.99^{\mathrm{b}}$ & $676.87 \pm 38.83^{\mathrm{b}}$ \\
7 & $206.94 \pm 83.21$ & $538.22 \pm 17.72^{\mathrm{a}}$ & $439.85 \pm 81.03^{\mathrm{b}}$ & $838.22 \pm 17.72^{\mathrm{b}}$ \\
14 & $246.17 \pm 28.58$ & $707.21 \pm 82.90^{\mathrm{a}}$ & $422.62 \pm 31.40^{\mathrm{b}}$ & $846.17 \pm 28.58^{\mathrm{b}}$ \\
21 & $342.51 \pm 47.25$ & $551.59 \pm 74.51^{\mathrm{a}}$ & $344.00 \pm 36.72^{\mathrm{b}}$ & 72.85 \\
F value & 1.66 & 202.04 & $<0.05$ & $433.55 \pm 54.55^{\mathrm{b}}$ \\
P-value & $>0.05$ & $<0.01$ & $<$ & \\
\hline
\end{tabular}

${ }^{\mathrm{a}} \mathrm{P}<0.05$ vs. neonatal-air group; ${ }^{\mathrm{b}}<0.05$ vs. neonatal-hyperoxia group.

Table III. Expression levels of $A T_{1} R$ and p22phox mRNA in rat lung tissues (n=6).

\begin{tabular}{|c|c|c|c|c|c|c|c|c|}
\hline \multirow[b]{2}{*}{$\begin{array}{l}\text { Time } \\
\text { (day) }\end{array}$} & \multicolumn{4}{|c|}{$A T_{l} R / G A P D H(\mathrm{OD})$} & \multicolumn{4}{|c|}{ p22phox/GAPDH (OD) } \\
\hline & $\begin{array}{c}\text { Neonatal- } \\
\text { air } \\
\text { group }\end{array}$ & $\begin{array}{l}\text { Neonatal- } \\
\text { hyperoxia } \\
\text { group }\end{array}$ & $\begin{array}{l}\text { Adult- } \\
\text { hyperoxia } \\
\text { group }\end{array}$ & $\begin{array}{l}\text { Neonatal- } \\
\text { intervention } \\
\text { group }\end{array}$ & $\begin{array}{l}\text { Neonatal- } \\
\text { air } \\
\text { group }\end{array}$ & $\begin{array}{l}\text { Neonatal- } \\
\text { hyperoxia } \\
\text { group }\end{array}$ & $\begin{array}{l}\text { Adult- } \\
\text { hyperoxia } \\
\text { group }\end{array}$ & $\begin{array}{c}\text { Neonatal- } \\
\text { intervention } \\
\text { group }\end{array}$ \\
\hline 1 & $0.21 \pm 0.08$ & $0.42 \pm 0.43^{\mathrm{a}}$ & $0.39 \pm 0.25$ & $0.39 \pm 0.61$ & $0.11 \pm 0.13$ & $0.39 \pm 0.01$ & $0.07 \pm 0.23^{\mathrm{b}}$ & $0.42 \pm 0.21$ \\
\hline 3 & $0.20 \pm 0.47$ & $0.66 \pm 0.13^{a}$ & $0.42 \pm 0.40^{\mathrm{b}}$ & $0.46 \pm 0.72^{\mathrm{c}}$ & $0.13 \pm 0.09$ & $0.52 \pm 0.41^{\mathrm{a}}$ & $0.11 \pm 0.19^{b}$ & $0.43 \pm 0.31^{\mathrm{c}}$ \\
\hline 7 & $0.30 \pm 0.16$ & $0.72 \pm 0.51^{\mathrm{a}}$ & $0.58 \pm 1.24^{b}$ & $0.47 \pm 1.31^{\mathrm{c}}$ & $0.11 \pm 0.03$ & $0.67 \pm 0.76^{\mathrm{a}}$ & $0.26 \pm 0.34^{\mathrm{b}}$ & $0.49 \pm 0.62^{c}$ \\
\hline 14 & $0.32 \pm 0.70$ & $0.79 \pm 1.90^{\mathrm{a}}$ & $0.66 \pm 0.71^{b}$ & $0.58 \pm 0.11^{\mathrm{c}}$ & $0.08 \pm 0.40$ & $0.87 \pm 0.27^{\mathrm{a}}$ & $0.41 \pm 0.25^{\mathrm{b}}$ & $0.32 \pm 0.77^{\mathrm{c}}$ \\
\hline 21 & $0.34 \pm 8.76$ & $0.80 \pm 0.25^{\mathrm{a}}$ & $0.68 \pm 0.07^{\mathrm{b}}$ & $0.66 \pm 0.39^{c}$ & $0.12 \pm 0.72$ & $0.66 \pm 1.62^{\mathrm{a}}$ & $0.38 \pm 0.33^{\mathrm{b}}$ & $0.34 \pm 0.04^{\mathrm{c}}$ \\
\hline F value & $0.73^{\mathrm{d}}$ & $127.53^{\mathrm{d}}$ & $72.85^{\mathrm{d}}$ & 130.80 & $0.89^{d}$ & $77.74^{\mathrm{d}}$ & $28.99^{d}$ & 31.39 \\
\hline P-value & $>0.05$ & $<0.01$ & $<0.05$ & & $>0.05$ & $<0.01$ & $<0.05$ & \\
\hline
\end{tabular}

${ }^{\mathrm{a}} \mathrm{P}<0.05$ vs. neonatal-air group; ${ }^{\mathrm{b}} \mathrm{P}<0.05$ vs. neonatal-hyperoxia group; ${ }^{\mathrm{C}} \mathrm{P}<0.05$ vs. neonatal-hyperoxia group; ${ }^{\mathrm{d}} \mathrm{P}<0.05$ comparison of different time points in the same group. $\mathrm{AT}_{1} \mathrm{R}$, angiotensin type 1 receptor; GAPDH, glyceraldehyde-3-phosphate dehydrogenase; OD, optical density.

group D at the corresponding time points, in contrast to the trend observed for AngII levels, suggesting that p22phox mRNA expression in the lung tissues may be regulated by AngII. The expression level of $A T_{l} R$ is also an impacting factor, as it would also affect the release of downstream ROS, and is potentially one of the reasons why in an environment with continuously high AngII levels, the lung injury in group D was markedly less evident than that in group B (Fig. 4).

Similar to the AngII levels, the $A T_{l} R$ and $p 22 p h o x$ mRNA levels in group $\mathrm{C}$ were significantly decreased compared with those in group B, and the differences were statistically significant $(\mathrm{P}<0.05$; Fig. 4).

ROS levels. The changes in ROS levels observed in the experimental groups were basically consistent with those of $p 22 p h o x$ mRNA, and groups B and D were combined for the univariate correlation analysis. The results showed that the ROS level was positively correlated with AngII as well as p22phox and $A T_{1} R$ mRNA expression $(\mathrm{r}=0.775, \mathrm{P}<0.01 ; \mathrm{r}=0.838, \mathrm{P}<0.01 ; \mathrm{r}=0.712$, $\mathrm{P}<0.05$, respectively), while statistical analysis of scatter plots revealed that the ROS level was not strictly linearly correlated with any of the indicators. Thus, the release of ROS might be the result of several factors.

Although the AngII content in group B was lower than that in group D on day 21, the levels of the downstream factors p22phox and ROS were not decreased. In some cases, the levels were even significantly higher than those in group D, suggesting that hyperoxic exposure might promote ROS production by the cells (Fig. 5). ROS are induced by AngII, and are also regulated by $\mathrm{AT}_{1} \mathrm{R}$ and other factors (17). The ROS levels in groups $\mathrm{C}$ and D on day 21 were significantly decreased compared with those in group B (Fig. 5B and C), suggesting that the reduced ROS levels might be associated with lesser lung damage in groups C and D.

TUNEL. AI values of the experimental groups are shown in Table IV and Fig. 6, and TUNEL images are shown in Fig. 7. In group $\mathrm{A}$, the lung sections showed no stained apoptotic AT-II cells at each time point (Fig. 7A), while in groups B and D, apoptosis of the AT-II cells was detected. The number of apoptotic cells increased as the time of hyperoxic exposure increased (Fig. 7B and C). However, in group D, the AI was significantly lower than that in group B. Although, apoptosis 
Table IV. Lung cell apoptosis index in the four groups $(n=6)$.

\begin{tabular}{lcccc}
\hline $\begin{array}{l}\text { Time } \\
\text { (day) }\end{array}$ & $\begin{array}{c}\text { Neonatal-air } \\
\text { group }\end{array}$ & $\begin{array}{c}\text { Neonatal-hyperoxia } \\
\text { group }\end{array}$ & $\begin{array}{c}\text { Neonatal-intervention } \\
\text { group }\end{array}$ & $\begin{array}{c}\text { Adult-hyperoxia } \\
\text { group }\end{array}$ \\
\hline 1 & $0.20 \pm 1.43$ & $3.55 \pm 1.55$ & $3.20 \pm 0.19$ & $1.39 \pm 0.91^{\mathrm{a}}$ \\
3 & $0.44 \pm 2.16$ & $3.87 \pm 1.83^{\mathrm{b}}$ & $2.53 \pm 0.99^{\mathrm{a}}$ & $1.87 \pm 0.83^{\mathrm{a}}$ \\
7 & $0.34 \pm 1.21$ & $5.22 \pm 1.72^{\mathrm{b}}$ & $3.85 \pm 1.03^{\mathrm{a}}$ & $3.22 \pm 0.72^{\mathrm{a}}$ \\
14 & $0.27 \pm 0.58$ & $7.21 \pm 1.90^{\mathrm{b}}$ & $4.62 \pm 1.40^{\mathrm{a}}$ & $3.17 \pm 0.57^{\mathrm{a}}$ \\
21 & $0.51 \pm 0.25$ & $5.59 \pm 1.51^{\mathrm{b}}$ & $3.00 \pm 0.72^{\mathrm{a}}$ & $3.55 \pm 0.51^{\mathrm{a}}$ \\
F value & 0.58 & 186.17 & 55.46 & \\
P-value & $>0.05$ & $<0.01$ & & \\
\hline
\end{tabular}

${ }^{\mathrm{a}} \mathrm{P}<0.05$ vs. neonatal-hyperoxia group; ${ }^{\mathrm{b}} \mathrm{P}<0.05$ vs. neonatal-air group.

A

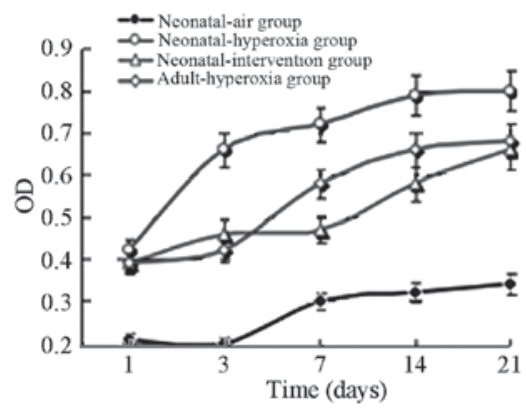

C
B



Neonatal-hyperoxia group

p22phox

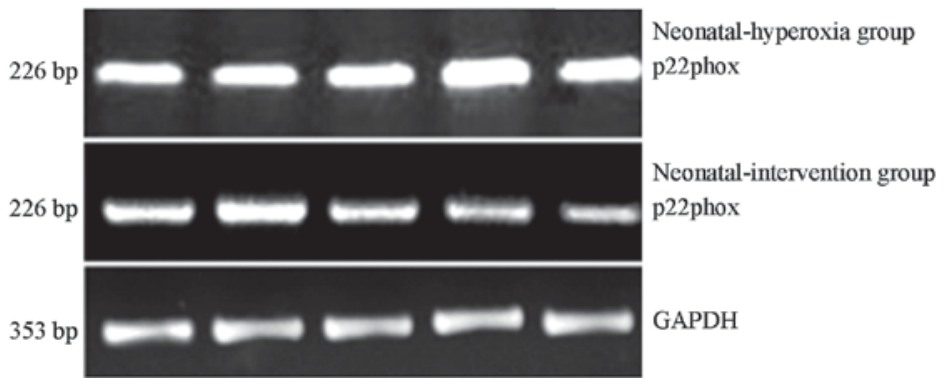

Figure 4. Changes in $A T_{l} R$ and $p 22 p h o x$ mRNA levels over time in the four groups. Changes in (A) $A T_{l} R$ and (B) $p 22 p h o x$ mRNA expression levels over time. (C) Impact of NK3201 on p22phox mRNA. AT ${ }_{1} \mathrm{R}$, angiotensin type 1 receptor.

was not completely inhibited by NK3201 in group C, the AI in group $\mathrm{C}$ was significantly decreased compared with that in group $\mathrm{B}(\mathrm{P}<0.05$; Table IV).

Caspase-3 expression. OD values determined by immunohistochemistry for caspase-3 in each experimental group are shown in Fig. 6. Following hyperoxic exposure, caspase-3 expression levels first increased then decreased. In contrast to AngII, caspase-3 levels in group B reached a peak on day 7 of exposure and then slowly declined (Fig. 6B). As the acute phase of hyperoxia-induced apoptosis passed, cells entered the late stage, namely the slow repair and fibrosis processes and caspase-3 levels were reduced. Analogously to the TUNEL results, caspase- 3 expression levels in groups $\mathrm{C}$ and $\mathrm{D}$ were significantly reduced compared with group $\mathrm{B}(\mathrm{P}<0.05$; Fig. $6 \mathrm{~B})$.

hOGGl and PPAR $\gamma$ expression. hOGG1 and PPAR $\gamma$ protein expression levels in group A were low. Hyperoxic exposure caused a rapid increase of hOGG1 and PPAR $\gamma$ protein expression, which reached a peak on the day 3 and then decreased gradually. hOGG1 and PPAR $\gamma$ protein expression in group D was higher than that in group $\mathrm{B}$, reached a peak on day 7 , and then began to decline, consistent with the apoptotic indicator levels measured above. hOGG1 and PPAR $\gamma$ expression in group $\mathrm{C}$ was significantly higher than that in group $\mathrm{B}$. The peak amplitudes of the increases were 23.01 and $28.90 \%$, respectively $(\mathrm{P}<0.05$; Table $\mathrm{V}$ and Fig. 8$)$, suggesting that the lung injury in group $\mathrm{C}$ was less severe than that in group B. The results indicated that the protective effects of NK3201 and inhibition of alveolar cell apoptosis were associated with cellular DNA damage repair.

\section{Discussion}

Morphogenesis of the human respiratory system may be divided into the embryonic stage, the pseudo-gland stage, the canaliculus stage, the uesicae stage and the alveolus stage (1). In rats, alveolar development occurs only in the uesicae stage at birth, which corresponds to 25-35 gestational weeks in humans (1). Thus, continuous hyperoxic exposure of newborn 


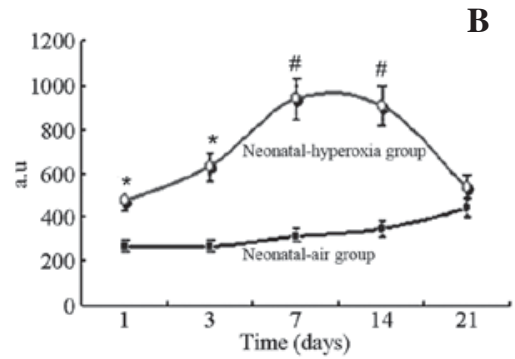

B



C

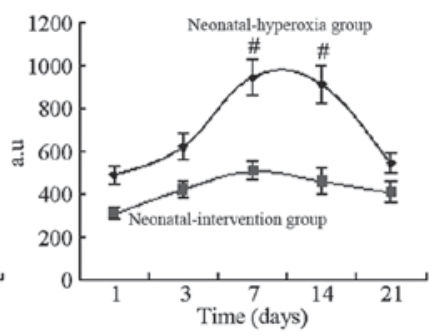

Figure 5. Comparison of ROS expression levels among the four groups. (A) Effects of hyperoxia on ROS expression; (B) comparison of ROS indicators at different developmental stages after hyperoxic exposure; (C) intervention effect of NK3201 on ROS. ${ }^{*} \mathrm{P}<0.05$, ${ }^{\#} \mathrm{P}<0.01$ between the two groups shown in each graph. ROS, reactive oxygen species; a.u., absorbance units.

A

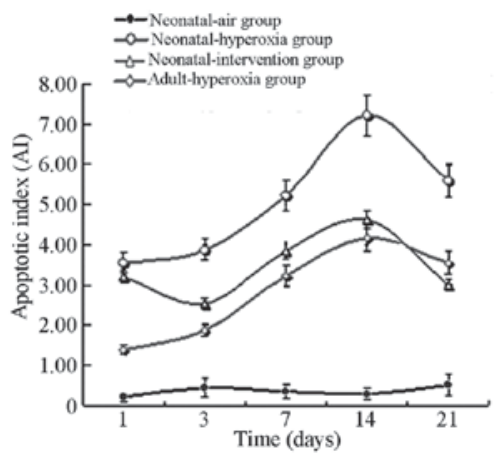

B



Figure 6. Comparison of AI and trends of integrated OD values of caspase- 3 in the four groups. (A) Comparison of AI and (B) trends of integrated OD values of caspase-3. " $\mathrm{P}<0.05$ vs. neonatal hyperoxia group. AI, apoptotic index; OD, optical density.



Figure 7. Apoptosis of lung tissue by TUNEL. (A) Apoptosis was rare in group A group (day 7). (B) Apoptosis was observed in group D (day 7). (C) The apoptosis in group B was more severe than that in group D (day 3). (D) The degree of apoptosis of group B was aggravated with prolonged hyperoxic exposure (day 7). (E) The degree of apoptosis in group C was decreased compared with that in group B (day 7). TUNEL, terminal deoxynucleotidyl transferase (TdT)-mediated dUTP nick end labeling.

rats might induce features such as alveolar maldevelopment and fibrosis, which are similar to those of ALI in human newborns $(13,14,16)$. In the present study, the untreated hyperoxic model group exhibited the typical intolerance to lack of oxygen on day 7 , which manifested mainly as breathing difficulties following deoxygenation, cyanosis and convulsions. These effects are similar to the clinical responses of newborns after the removal of hyperoxic mechanical ventilation. Following hyperoxic exposure, H\&E staining and electron microscopy experiments indicated the presence of lung injury and fibrosis, suggesting that the rat hyperoxia model was successfully established. This model is essential for the study of neonatal hyperoxia $(13,14,16)$.

A previous study found that in human fibrotic lung tissue, fibroblasts produce a factor, later confirmed as angiotensinogen, that induces the apoptosis of alveolar epithelial cells (18). With in-depth studies of the RAS, it has been found that AngII might stimulate the proliferation of fibroblasts, chemotactically drives inflammatory cells, and promotes the apoptosis of AT-II cells, indicating its role in the fibrotic pathogenesis of multiple organs $(18,19)$. Studies have confirmed that the AngII receptor is widely expressed in the alveolar epithelium (20) 
Table V. Protein expression of hOGG1 and PPAR $\gamma$ in rat lung tissues $(n=6)$.

\begin{tabular}{|c|c|c|c|c|c|c|c|c|}
\hline \multirow[b]{2}{*}{$\begin{array}{l}\text { Time } \\
\text { (day) }\end{array}$} & \multicolumn{4}{|c|}{ hOGG1 } & \multicolumn{4}{|c|}{ PPAR $\gamma$} \\
\hline & $\begin{array}{l}\text { Neonatal- } \\
\text { air } \\
\text { group }\end{array}$ & $\begin{array}{l}\text { Neonatal- } \\
\text { hyperoxia } \\
\text { group }\end{array}$ & $\begin{array}{l}\text { Neonatal- } \\
\text { intervention } \\
\text { group }\end{array}$ & $\begin{array}{l}\text { Adult- } \\
\text { hyperoxia } \\
\text { group }\end{array}$ & $\begin{array}{l}\text { Neonatal- } \\
\text { air } \\
\text { group }\end{array}$ & $\begin{array}{l}\text { Neonatal- } \\
\text { hyperoxia } \\
\text { group }\end{array}$ & $\begin{array}{l}\text { Neonatal- } \\
\text { intervention } \\
\text { group }\end{array}$ & $\begin{array}{l}\text { Adult- } \\
\text { hyperoxia } \\
\text { group }\end{array}$ \\
\hline 1 & $109.22 \pm 0.08$ & $220.57 \pm 0.43^{a}$ & $249.42 \pm 0.23$ & $366.49 \pm 0.61^{\mathrm{b}}$ & $213.31 \pm 0.23$ & $227.07 \pm 0.23$ & $342.44 \pm 1.21^{\mathrm{a}}$ & $201.49 \pm 0.01$ \\
\hline 3 & $96.32 \pm 0.47$ & $288.66 \pm 0.51^{\mathrm{a}}$ & $461.59 \pm 0.41^{\mathrm{a}}$ & $481.46 \pm 0.72^{b}$ & $196.33 \pm 0.08$ & $424.11 \pm 0.19^{a}$ & $550.34 \pm 0.34^{\mathrm{a}}$ & $729.52 \pm 0.41^{b}$ \\
\hline 7 & $107.37 \pm 0.16$ & $279.66 \pm 0.13^{a}$ & $451.74 \pm 1.25^{\mathrm{a}}$ & $599.47 \pm 1.31^{b}$ & $189.28 \pm 0.03$ & $409.26 \pm 0.34^{\mathrm{a}}$ & $598.32 \pm 1.64^{\mathrm{a}}$ & $786.67 \pm 0.76^{b}$ \\
\hline 14 & $110.31 \pm 0.70$ & $161.0 \pm 81.90^{\mathrm{a}}$ & $327.82 \pm 0.77^{\mathrm{a}}$ & $353.58 \pm 0.11^{\mathrm{b}}$ & $203.34 \pm 1.40$ & $303.41 \pm 0.25^{\mathrm{a}}$ & $604.49 \pm 1.77^{\mathrm{a}}$ & $553.87 \pm 0.27^{\mathrm{b}}$ \\
\hline 21 & $104.43 \pm 88.76$ & $129.0 \pm 0.25$ & $225.91 \pm 0.15^{\mathrm{a}}$ & $276.66 \pm 0.39^{b}$ & $220.27 \pm 1.72$ & $244.38 \pm 0.33$ & $412.37 \pm 0.64^{\mathrm{a}}$ & $379.66 \pm 1.62^{b}$ \\
\hline F value & 0.39 & 127.53 & 98.80 & 272.85 & 0.66 & 707.74 & 131.39 & 228.99 \\
\hline P-value & $>0.05$ & $<0.01$ & $<0.05$ & $<0.01$ & $>0.05$ & $<0.01$ & $<0.05$ & $<0.01$ \\
\hline
\end{tabular}

${ }^{\mathrm{a}} \mathrm{P}<0.05$ vs. neonatal-hyperoxia group; ${ }^{\mathrm{b}} \mathrm{P}<0.05$ vs. neonatal-air group. hOGG1, human 8-oxogyanine-DNA glycosylase 1 ; PPAR $\gamma$, peroxisome proliferator-activated receptor- $\gamma$.
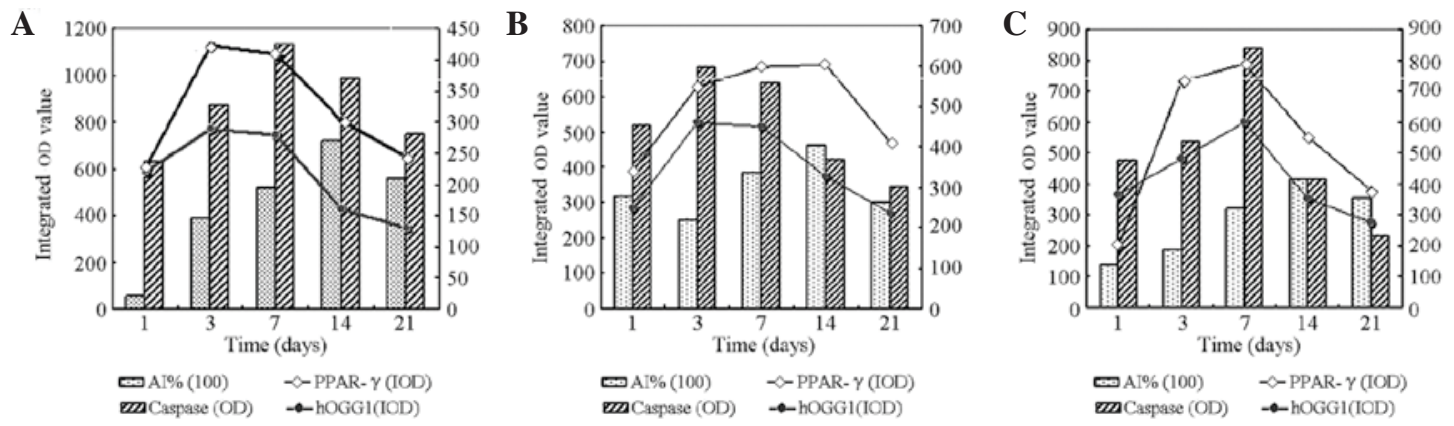

Figure 8. Comparison chart of retrieval indicators (PPAR $\gamma$ and hOGG1) with apoptosis-related indicators. (A) Neonatal-hyperoxia group; (B) neonatal-intervention group; (C) adult-hyperoxia group. PPAR $\gamma$, peroxisome proliferator-activated receptor- $\gamma$; hOGG1, human 8-oxogyanine-DNA glycosylase 1; OD, optical density; AI, apoptosis index.

and its expression is significantly increased during hyperoxic injury (21). Other studies have shown that, through inhibiting AngII and its receptor, hyperoxia-induced collagen deposition in the lung tissue could be reduced, thus reversing the occurrence of pulmonary fibrosis $(21,22)$. However, the specific molecular mechanism is not yet fully understood.

The close relationship between hyperoxic lung injury and ROS $(8,23)$, has led to attention being focused on the regulatory roles of the AngII-p22phox-ROS signaling pathway. ROS are important signaling molecules that can regulate vascular strain and structures and induce the expression of redox-sensitive genes through various intracellular or intercellular signaling pathways, activating a series of inflammatory reactions. Thus, ROS are among the main factors that can mediate ALI $(23,24)$. p22phox is the active subunit of nicotinamide adenine dinucleotide/nicotinamide adenine dinucleotide phosphate oxidase (NADH/NADPH), which is a major enzyme involved in ROS generation. Previous studies demonstrated that the AngII-p22phox-ROS signaling pathway is closely associated with cardiovascular diseases such as hypertension, arteriosclerosis, renal vascular and vascular remodeling-pulmonary hypertension $(25,26)$. However, whether it is involved in the mechanism of hyperoxic injury of AT-II cells remained unclear. Moreover, the relationship between apoptosis and retrieval is not clearly understood, and whether inhibiting this pathway reduces apoptosis, enhances recovery, and attenuates the hyperoxic injury is unclear; these are important issues to be considered.

The present study indicated that hyperoxic exposure induced an increase in the expression levels of proteins involved in the AngII-p22phox-ROS signaling pathway. In particular, when ROS levels were significantly increased, the morphological changes of lung tissues were much more evident. Apoptosis and caspase- 3 expression were also higher, suggesting that the RAS might be involved in the occurrence and development of hyperoxia-induced lung injury and pulmonary fibrosis through the AngII-p22phox-ROS signaling pathway.

With the prolonged time of hyperoxic exposure, the $\mathrm{AT}_{1} \mathrm{R}$ level in the lung tissues of the model group gradually increased, in contrast to p22phox mRNA, which decreased with AngII, indicating that $\mathrm{AT}_{1} \mathrm{R}$ expression was not only regulated by AngII. The hyperoxic exposure increased p22phox mRNA and ROS expression levels. Its effects on the lung development of newborn rats might involve the upregulation of $\mathrm{AT}_{1} \mathrm{R}$ expression inside the lung cells. The $\mathrm{AT}_{1} \mathrm{R}$ is one of the major receptors through which AngII promotes cellular mitosis and 
proliferation inside the lung, binds AngII in a dose-dependent manner, and promotes the proliferation and activation of human lung fibroblasts, inducing collagen deposition in the lung tissue $(21,22)$. These data suggest that this pathway is one of the major pathways involved in the development of hyperoxia-induced lung injury and secondary pulmonary fibrosis.

During the present study, it was also observed that, under the same experimental conditions, the lung injury and the levels of p22phox mRNA, ROS, caspase-3 and other apoptotic indices in the lung tissues in group B were significantly higher than those in group $\mathrm{D}$. Additionally, $\mathrm{AT}_{1} \mathrm{R}$ expression in group B was higher than that in group D. This may be due to the fact that, under these conditions, AngII levels were lower than that in group D. The higher ROS levels observed in group B suggest that newborn rats are much more sensitive to hyperoxia than are adult rats, which induces oxidative stress responses in the lung tissues.

PPAR $\gamma$ is a member of the ligand-activated nuclear transcription factor superfamily and is involved in many physiological and pathological activities in vivo. It is able to inhibit the activities of multiple nuclear factors such as NF- $\mathrm{kB}, \mathrm{AP}-1$, STAT-1 and Jun, and regulates cellular survival as well as the expression of proteins, cytokines, and chemokines after activation. Furthermore, it inhibits endothelial cell apoptosis and reduces the recruitment of inflammatory cells $(10,27,28)$. hOGG1 is a single base excision-retrieval enzyme; its most important function is to repair oxidative DNA damage and to maintain DNA stability (12). Low levels of hOGG1 indicate that the cellular capacity of DNA repair is decreased. The cell cycle would be blocked at the G0/G1 phase, slowing down cell proliferation, and causing an increase in apoptosis and reduced survival rate (12). The roles of the aforementioned species in neonatal hyperoxic injury and their correlation with RAS and the AngII-p22phox-ROS pathway have not been thoroughly elucidated.

In the present study, increased expression levels of PPAR $\gamma$ and hOGG1 appeared rapidly after hyperoxic exposure. Their expression reached a peak earlier than did that of AngII and ROS. This effect may be attributed to the body's protective reactions to the stimulatory effect of oxidative damage. PPAR $\gamma$ and hOGG1 expression levels were reduced at a later time point, indicating that the repair capacities of anti-injury genes were limited. Thus, apoptosis occurred in a large number of cells, including functional cells such as AT-II cells, which eventually resulted in the insufficient retrieval of alveolar epithelial cells and pulmonary fibrosis. Therefore, whether only after successfully reducing the hyperoxia-induced elevated level of AngII, opposing the oxidation, and increasing the active repair, were the AT-II cells able to avoid apoptosis and play their role in repairing the alveolar epithelium remained to be determined. To verify this hypothesis, a chymotrypsin inhibitor was used.

The process through which AngI is transformed into AngII involves the angiotensin-converting enzyme (ACE) pathway and the non-ACE pathway. The chymotrypsin pathway is an important non-ACE pathways. In the heart and lung, AngII is mainly generated through the chymotrypsin pathway, so the effects of angiotensinase inhibitors towards ALI are limited (29). It may also promote the conversion of endothelin 1, inactivate bradykinin and pancreatic bradykinin, degrade substance $\mathrm{P}$, and promote collagen generation $(30,31)$. In vitro studies have demonstrated that chymotrypsin inhibitors are able to block fibroblasts in the G0/G1 phase, delay their cell cycle, and inhibit their proliferation. Chymotrypsin inhibitors are also able to inhibit the proliferation and differentiation of myocardial interstitial cells $(30,31)$. In the present study, the specific chymotrypsin inhibitor NK3201 was used.

The results demonstrated that NK3201 significantly reduced the hyperoxia-induced increases in AngII expression levels, reduced ROS production, and significantly reduced the expression of apoptosis-related enzymes, while the expression of anti-damage proteins, PPAR- $\gamma$ and hOGG1, were significantly increased by NK3201, indicating that this chymotrypsin inhibitor effectively inhibits the negative roles of RAS in the lung, reduces the apoptosis of alveolar cells, and improves the repair abilities of lung functional cells. Thus, the hyperoxia-induced lung injury and the prognosis of pulmonary fibrosis may be improved through multiple mechanisms. Although the present study used an animal model, it provides a clear direction for the alleviation of neonatal hyperoxia-induced lung injury, which warrants investigation in further studies.

\section{Acknowledgements}

This study was supported by the Medical Scientific Research Project in Chongqing, China (grant no. 20141003). The Natural Science Foundation Project of Chongqing Science and Technology Commission (CSTC), China (grant no. cstc2013jcyjA10104).

\section{References}

1. Stocks J, Hislop A and Sonnappa S: Early lung development: Lifelong effect on respiratory health and disease. Lancet Respir Med 1: 728-742, 2013.

2. Heching HJ, Turner M, Farkouh-Karoleski C and Krishnan U: Pulmonary vein stenosis and necrotising enterocolitis: Is there a possible link with necrotising enterocolitis? Arch Dis Child Fetal Neonatal Ed 99: F282-F285, 2014.

3. Iliodromiti Z, Zygouris D, Sifakis S, Pappa KI, Tsikouras P, Salakos N, Daniilidis A, Siristatidis C and Vrachnis N: Acute lung injury in preterm fetuses and neonates: Mechanisms and molecular pathways. J Matern Fetal Neonatal Med 26: 1696-1704, 2013.

4. Wang J, Liu W, Peng Y, Li W, Cheng T, Gao C, Mo L, Zhao Z and Chang L: Synergetic effect of $\alpha$-lipoic acid with keratinocyte growth factor on protecting alveolar epithelial type II cells of rat fetus from hyperoxia-induced injury. Cell Physiol Biochem 33: 953-966, 2014.

5. Dikalov SI and Nazarewicz RR: Angiotensin II-induced production of mitochondrial reactive oxygen species: Potential mechanisms and relevance for cardiovascular disease. Antioxid Redox Signal 19: 1085-1094, 2013.

6. Wagenaar GT, Sengers RM, Laghmani el H, Chen X, Lindeboom MP, Roks AJ, Folkerts G and Walther FJ: Angiotensin II type 2 receptor ligand PD123319 attenuates hyperoxia-induced lung and heart injury at a low dose in newborn rats. Am J Physiol Lung Cell Mol Physiol 307: L261-L272, 2014.

7. Vyas-Read S, Wang W, Kato S, Colvocoresses-Dodds J, Fifadara NH, Gauthier TW, Helms MN, Carlton DP and Brown LA: Hyperoxia induces alveolar epithelial-to-mesenchymal cell transition. Am J Physiol Lung Cell Mol Physiol 306: L326-L340, 2014.

8. Youn JY, Zhang J, Zhang Y, Chen H, Liu D, Ping P, Weiss JN and Cai H: Oxidative stress in atrial fibrillation: An emerging role of NADPH oxidase. J Mol Cell Cardiol 62: 72-79, 2013. 
9. Bruce E, Shenoy V, Rathinasabapathy A, Espejo A, Horowitz A Oswalt A, Francis J, Nair A, Unger T, Raizada MK, et al: Selective activation of angiotensin AT2 receptors attenuates progression of pulmonary hypertension and inhibits cardiopulmonary fibrosis. Br J Pharmacol 172: 2219-2231, 2015.

10. Mohamed TL, Nguyen HT, Abdul-Hafez A, Dang VX, Dang MT, Gewolb IH and Uhal BD: Prior hypoxia prevents downregulation of ACE-2 by hyperoxia in fetal human lung fibroblasts. Exp Lung Res 42: 121-130, 2016

11. Morales E, Sakurai R, Husain S, Paek D, Gong M, Ibe B, Li Y, Husain M, Torday JS and Rehan VK: Nebulized PPAR $\gamma$ agonists: A novel approach to augment neonatal lung maturation and injury repair in rats. Pediatr Res 75: 631-640, 2014.

12. Koval VV, Knorre DG and Fedorova OS: Structural features of the interaction between human 8-Oxoguanine DNA glycosylase hOGG1 and DNA. Acta Naturae 6: 52-65, 2014.

13. Yang L, Liu C, Dang H, Fang F, Tan L, Zhao P, Xu F and Liu C: Substance $\mathrm{P}$ attenuates hyperoxia induced lung injury in neonatal rats. Mol Med Rep 9: 595-599, 2014

14. Liu C, Yang L, Dang H, Fang F and Xu F: Effect of Substance P on type II alveolar epithelial cells exposed to hyperoxia and its regulation of the Sonic hedgehog signaling pathway. Mol Med Rep 10: 1604-1608, 2014.

15. Qi XJ, Ning W, Xu F, Dang HX, Fang F and Li J: Fasudil, an inhibitor of Rho-associated coiled-coil kinase, attenuates hyperoxia-induced pulmonary fibrosis in neonatal rats. Int J Clin Exp Pathol 8: 12140-12150, 2015.

16. Dang H, Yang L, Wang S, Fang F and Xu F: Calcitonin gene-related peptide ameliorates hyperoxia-induced lung injury in neonatal rats. Tohoku J Exp Med 227: 129-138, 2012.

17. Lu G, Xu C, Tang K, Zhang J, Li Q, Peng L, Wang Y, Huang Z and Gao X: H2S inhibits angiotensin II-induced atrial Kv1.5 upregulation by attenuating Nox4-mediated ROS generation during atrial fibrillation. Biochem Biophys Res Commun 483 534-540, 2017

18. Kaparianos A and Argyropoulou E: Local renin-angiotensin II systems, angiotensin-converting enzyme and its homologue ACE2: Their potential role in the pathogenesis of chronic obstructive pulmonary diseases, pulmonary hypertension and acute respiratory distress syndrome. Curr Med Chem 18: 3506-3515, 2011.

19. Uhal BD, Kim JK, Li $X$ and Molina-Molina M: Angiotensin-TGF-beta 1 crosstalk in human idiopathic pulmonary fibrosis: Autocrine mechanisms in myofibroblasts and macrophages. Curr Pharm Des 13: 1247-1256, 2007.

20. Ashry O, Schnecko A, Clauss WG and Fronius M: Evidence for expression and function of angiotensin II receptor type 1 in pulmonary epithelial cells. Respir Physiol Neurobiol 195: 37-40, 2014.
21. Chou HC, Lang YD, Wang LF, Wu TY, Hsieh YF and Chen CM: Angiotensin II type 1 receptor antagonist attenuates lung fibrosis in hyperoxia-exposed newborn rats. J Pharmacol Exp Ther 340: 169-175, 2012.

22. Yaguchi S, Ogawa Y, Shimmura S, Kawakita T, Hatou S, Satofuka S, Nakamura S, Imada T, Miyashita H, Yoshida S, et al: Angiotensin II type 1 receptor antagonist attenuates lacrimal gland, lung, and liver fibrosis in a murine model of chronic graft-versus-host disease. PLoS One 8: e64724, 2013.

23. Li Z, Fang F and Xu F: Effects of different states of oxidative stress on fetal rat alveolar type II epithelial cells in vitro and ROS-induced changes in Wnt signaling pathway expression. Mol Med Rep 7: 1528-1532, 2013

24. Berkelhamer SK, Kim GA, Radder JE, Wedgwood S, Czech L, Steinhorn RH and Schumacker PT: Developmental differences in hyperoxia-induced oxidative stress and cellular responses in the murine lung. Free Radic Biol Med 61: 51-60, 2013.

25. Fang C, Liu Y, Lu P, Liang Q, Liu X, Zhao W and Su W: Total saponins of panax ginseng inhibiting human endothelium cells' damages induced by angiotensin II via AT1 receptor. J Ethnopharmacol 138: 439-444, 2011.

26. Peng ZZ, Hu GY, Shen H, Wang L, Ning WB, Xie YY, Wang NS, Li BX, Tang YT and Tao LJ: Fluorofenidone attenuates collagen I and transforming growth factor-betal expression through a nicotinamide adenine dinucleotide phosphate oxidase-dependent way in NRK-52E cells. Nephrology (Carlton) 14: 565-572, 2009.

27. Rehan VK, Fong J, Lee R, Sakurai R, Wang ZM, Dahl MJ, Lane RH, Albertine KH and Torday JS: Mechanism of reduced lung injury by high-frequency nasal ventilation in a preterm lamb model of neonatal chronic lung disease. Pediatr Res 70: 462-466, 2011.

28. Martin CR, Zaman MM, Gilkey C, Salguero MV, Hasturk H, Kantarci A, Van Dyke TE and Freedman SD: Resolvin D1 and lipoxin A4 improve alveolarization and normalize septal wall thickness in a neonatal murine model of hyperoxia-induced lung injury. PLoS One 9: e98773, 2014.

29. Li S, Wang X, Li Y, Jr CKK and Martin DS: Bortezomib, a proteasome inhibitor, attenuates angiotensin II-induced hypertension and aortic remodeling in rats. PLoS One 8: e78564, 2013.

30. Doggrell SA and Wanstall JC: Vascular chymase: Pathophysiological role and therapeutic potential of inhibition. Cardiovasc Res 61: 653-662, 2004.

31. Yahiro E, Miura S, Imaizumi S, Uehara Y and Saku K: Chymase inhibitors. Curr Pharm Des 19: 3065-3071, 2013. 